\title{
Multiple Pathogens Prevalent in Shrimp Penaeus vannamei Cultured from Greenhouse Ponds in Jiangsu Province of China
}

\author{
Hui Shen ${ }^{1,2}$, Ge Jiang ${ }^{1,2}$, Xihe Wan ${ }^{1 *}$, Xianping Fan ${ }^{1}$, Yi Qiao ${ }^{1}$, Wenjun Shi ${ }^{1,3}$, Hui Li ${ }^{1}$, and Libao Wang ${ }^{1}$ \\ ${ }^{1}$ Institute of Oceanology and Marine Fisheries, Jiangsu, PR China \\ ${ }^{2}$ College of Fisheries and Life Sciences, Shanghai Ocean University, Shanghai, PR China \\ ${ }^{3}$ Chinese Academy of Sciences, Yantai, Shandong, PR China
}

\begin{abstract}
In recent years, several pathogens have emerged and caused heavy mortality in Asia. In this study, we investigated the prevalence of pathogens in specimens of whiteleg shrimp (Penaeus vannamei) collected from greenhouse ponds. In total, six pathogens were tested in these shrimp, three of which, including Enterocytozoon hepatopenaei (EHP), acute hepatopancreatic necrosis disease (AHPND)-causing Vibrio parahaemolyticus and infectious hypodermal and haematopoietic necrosis virus (IHHNV), were detected in shrimp aquaculture, with EHP being the most prevalent; Taura syndrome virus (TSV), White spot syndrome virus (WSSV) and yellow head virus (YHV) were not detected in these samples. Ultrastructure examination revealed the presence of a large number of EHP spores infecting hepatopancreatic epithelial cells of shrimp. Body weight (BW), body length (BL) and BW/BL ratio, revealed growth retardation among EHP-infected shrimp, as indicated by the significantly lower values of BW, $\mathrm{BL}$ and $\mathrm{BW} / \mathrm{BL}$ ratio in these shrimps than those in EHP-uninfected shrimp $(\mathrm{P}<0.05)$. Together, these data indicated that EHP causes severe growth retardation of shrimp and is a major pathogen of aquacultured shrimp culturing in greenhouse ponds in Jiangsu Province; effective measures should be undertaken to control its spread.
\end{abstract}

Keywords: Penaeus vannamei; Shrimp aquaculture; Enterocytozoon hepatopenaei; Greenhouse ponds

\section{Introduction}

In recent years, shrimp culture industries have suffered serious economic losses due to attacking by several newly emerged pathogens in Asia and shrimp production in China also decreased up to $35 \%$ of last 5 years' production. AHPND sometimes also called early mortality syndrome (EMS), an emerging pathogen, which was the most serious bacterial pathogen that has caused serious losses to shrimp farmers in Asian Countries from 2007 [1-3]. AHPND infection resulted by Vibrio parahaemolyticus, which colonized shrimp stomach and produced soluble toxins that caused massive cell sloughing [4,5]. Subsequently, a new microsporidian species [6,7], identified in growth-retarded black tiger shrimp Penaeus monodon cultured in Thailand [8], has also caused serious losses to shrimp aquaculture, which was underestimated since it could not cause serious mortality but grow-retardation after infection [7,9]. EHP, within the genus Enterocytozoon. Santhoshkumar et al. [10] also demonstrated that EHP damages hepatopancreatic epithelial cells by changing their biochemical parameters. EHP infection often associated with white feces syndrome [11]. In addition to newly emerged pathogens, WSSV, YHV, IHHNV, TSV still as the serious diseases threat to shrimp farmers are most lethal, especially WSSV was the most serious pathogen in terms of overall production losses due to high virulence [12-16].

Given high prevalence of pathogens, government and shrimp farmers had many efforts to overcome obstacles confronted shrimp culture, including SPF breeding stocks, strict pathogens quarantine, standard management strategies. Shrimp farmers in Jiangsu province in China has initiated greenhouse shrimp culture mode characterizing 600 $\mathrm{m}^{2}$ individually and approximately $1 \mathrm{~m}$ water depth. Since it had merit of isolation of pathogens one by one and convenient management of water quality, the greenhouse culture mode was proved to be successful for shrimp culture.

This work reported herein was conducted to investigate the prevalence of single or dual to multiple pathogens in shrimp, we analyzed shrimp collected from greenhouse ponds at the time of harvest in Jiangsu Province of China, and discussed whether any of pathogens or one pathogen was correlated with the economic losses.

\section{Material and Methods}

\section{Shrimp specimens}

A total of 360 shrimp specimens were collected from 20 greenhouse ponds from Jiangsu province of China from $7^{\text {th }}$ to $14^{\text {th }}$ September 2016. Approximately 20 shrimp individuals were randomly collected per pond, measured the size and frozen for the detection of pathogens, the 3 individuals per pond were fixed for ultrastructure examination. The shrimp specimens were categorized to healthy and grow-retarded groups according to growth performance told by shrimp farmers (Figure 1).

\section{Electron microscopy}

Small pieces of hepatopancreatic, intestinal tract tissues from the shrimp which examined by light microscopy were fixed in $2.5 \%$ glutaraldehyde, in Millonig buffer followed by routine method [8]. Sections were examined using PHLIP transmission electron microscopy.

\section{Nucleic acid isolation}

Hepatopancreatic tissue was homogenised in lysis buffer $(50 \mathrm{mM}$ Tris- $\mathrm{HCl}, 50 \mathrm{mM}$ EDTA, $1 \%$ SDS, $100 \mathrm{mM} \mathrm{NaCl}$, pH 8.0) containing 20 $\mathrm{mg} \mathrm{L}^{-1}$ proteinase $\mathrm{K}$. DNA was isolated and purified using the phenolchloroform method. For PCR, all DNA templates were adjusted to

*Corresponding author: Xihe Wan, Institute of Oceanology and Marine Fisheries, Jiangsu 226007, PR China, Tel: 862161900304; E-mail: 2061141170@qq.com

Received November 10, 2017; Accepted December 01, 2017; Published December 06, 2017

Citation: Shen H, Jiang G, Wan X, Fan X, Qiao Y, et al. (2017) Multiple Pathogens Prevalent in Shrimp Penaeus vannamei Cultured from Greenhouse Ponds in Jiangsu Province of China. J Aquac Res Development 8: 516. doi: 10.4172/21559546.1000516

Copyright: ( $) 2017$ Shen $\mathrm{H}$, et al. This is an open-access article distributed under the terms of the Creative Commons Attribution License, which permits unrestricted use, distribution, and reproduction in any medium, provided the original author and source are credited. 
Citation: Shen H, Jiang G, Wan X, Fan X, Qiao Y, et al. (2017) Multiple Pathogens Prevalent in Shrimp Penaeus vannamei Cultured from Greenhouse Ponds in Jiangsu Province of China. J Aquac Res Development 8: 516. doi: 10.4172/2155-9546.1000516

Page 2 of 5

a concentration of $100 \mathrm{ng} \mu \mathrm{l}-1$ with distilled water. Total RNA was extracted from gill tissues of the shrimp using TaKaRa MiniBEST Viral RNA Extraction Kit Ver. 5. 0.

\section{PCR and RT-PCR analysis}

Purified DNA templates of all samples were examined to test the presence of various shrimp pathogens, including WSSV, IHHNV, EHP, and acute hepatopancreatic necrosis disease (AHPND)-causing V. Parahaemolyticus. Total RNA isolated from gill tissues was used for cDNA synthesis using SMARTScribe Reverse Transcriptase (Clontech) and oligo-dT primer. The cDNA was then used as the template for detecting TSV and YHV. Primers used for various PCRs are provided in Table 1.

\section{Statistical tests}

Statistical analysis was done using SPSS software version 20. A t-test was used for comparison of paired data after passing normality and equal variance tests. One-way analysis of variance (ANOVA) was performed for all multiple comparisons using the Student-Newmankeuls methods. Difference were considered to be statistically significant at $\mathrm{P} \leq 0.05$. Graphic plots with linear regressions were performed using SigmaPlot version 12.5 software.

\section{Results}

\section{Ultrastructure}

TEM examination of grow-retarded shrimp did not show obvious cytopathic changes in tubular epithelial cells of hepatopancreas, except for the presence EHP surrounding cytoplasm. Large number of EHP spores were found in tubular epithelial cells of hepatopancreas (Figure 2a). Mature spores comprised an anchoring disk, polar filament and polaroplast; the spore wall comprised a cell membrane with an electrontransparent endospore $(\sim 10 \mathrm{~nm})$ and an electron-dense exospore $(\sim 2$ $\mathrm{nm}$ ) (Figure 2b).

\section{PCR analysis}

Among the 6 pathogens tested, EHP, IHHNV, AHPND and WSSV were detected. EHP, a newly emerged pathogen, was the high prevalence in grow-retarded shrimps in this study (Table 2). Notably,
EHP positive ratio of grow-retarded shrimps was $12 \%$ in the first-step PCR having a production of $779 \mathrm{bp}$ which indicated heavily infected with EHP. Meanwhile, positive EHP ratio of healthy shrimp was $0 \%$. The following high prevalent pathogen were IHHNV, AHPND. In this study, WSSV, TSV and YHV were not detected in all shrimps.

The relationship between pathogens and Body length (BL), body weight $(\mathrm{BW})$ and ratio of $\mathrm{BW} / \mathrm{BL}$

BL and BW of healthy shrimp group were significantly higher than those of growth-retarded group $(\mathrm{P}<0.05)$ (Table 2). According to PCR results, Uninfected group (156 individuals), EHP-infected group

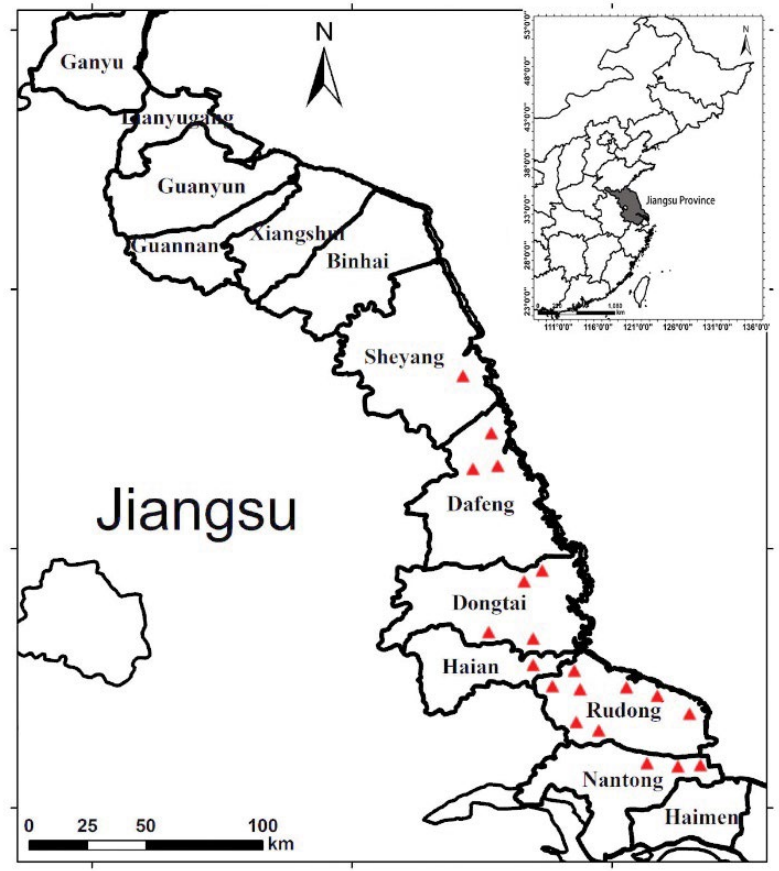

Figure 1: Sites in Jiangsu province. The shrimp were sampled from greenhouse Sampling ponds.

\begin{tabular}{|c|c|c|c|}
\hline Pathogens item & Primers & Primer sequence & Reference \\
\hline \multirow{4}{*}{ WSSV } & W-F1 & ACTACTAACTTCAGCCTATCTAG & \multirow{4}{*}{ [13] } \\
\hline & W-R1 & TAATGCGGGTGTAATGTTCTTA & \\
\hline & W-F2 & GTAACTGCCCСTTCCATCTCCA & \\
\hline & W-R2 & TACGGCAGCTGCTGCACCTTGT & \\
\hline \multirow{2}{*}{ IHHNV } & $389 \mathrm{~F}$ & CGGAACACAACCCGACTTTA & \multirow{2}{*}{ [14] } \\
\hline & $389 \mathrm{R}$ & GGCCAAGACCAAAATACGAA & \\
\hline \multirow{2}{*}{ AHPND } & AP3-F & ATGAGTAACAATATAAAACATGAAAC & \multirow{2}{*}{ [5] } \\
\hline & AP3-R & GTGGTAATAGATTGTACAGAA & \\
\hline \multirow{2}{*}{ TSV } & $55 \mathrm{P} 1$ & GGCGTAGTGAGTAATGTAGC & \multirow{2}{*}{ [15] } \\
\hline & 55P2 & CTTCAGTGACCACGGTATAG & \\
\hline \multirow{4}{*}{ EHP } & ENF779 & CAGCAGGCGCGAAAATTGTCCA & \multirow{4}{*}{ [16] } \\
\hline & ENR779 & AAGAGATATTGTATTGCGCTTGCTG & \\
\hline & ENF176 & CAACGCGGGAAAACTTACCA & \\
\hline & ENR176 & ACCTGTTATTGCCTTCTCCСTCC & \\
\hline \multirow{4}{*}{ YHV } & YHV5f & CGTATTGCATCGAACGTCACTG & \multirow{4}{*}{ [17] } \\
\hline & YHV5r & CAAGATCACTAATAACGCCTGATGC & \\
\hline & YHV2s & CGGGGTTACCCGCTTATATT & \\
\hline & YHV2as & GCCTGAGGTGAAGTCCATGT & \\
\hline
\end{tabular}

Table 1: The primers for detection of pathogens. 


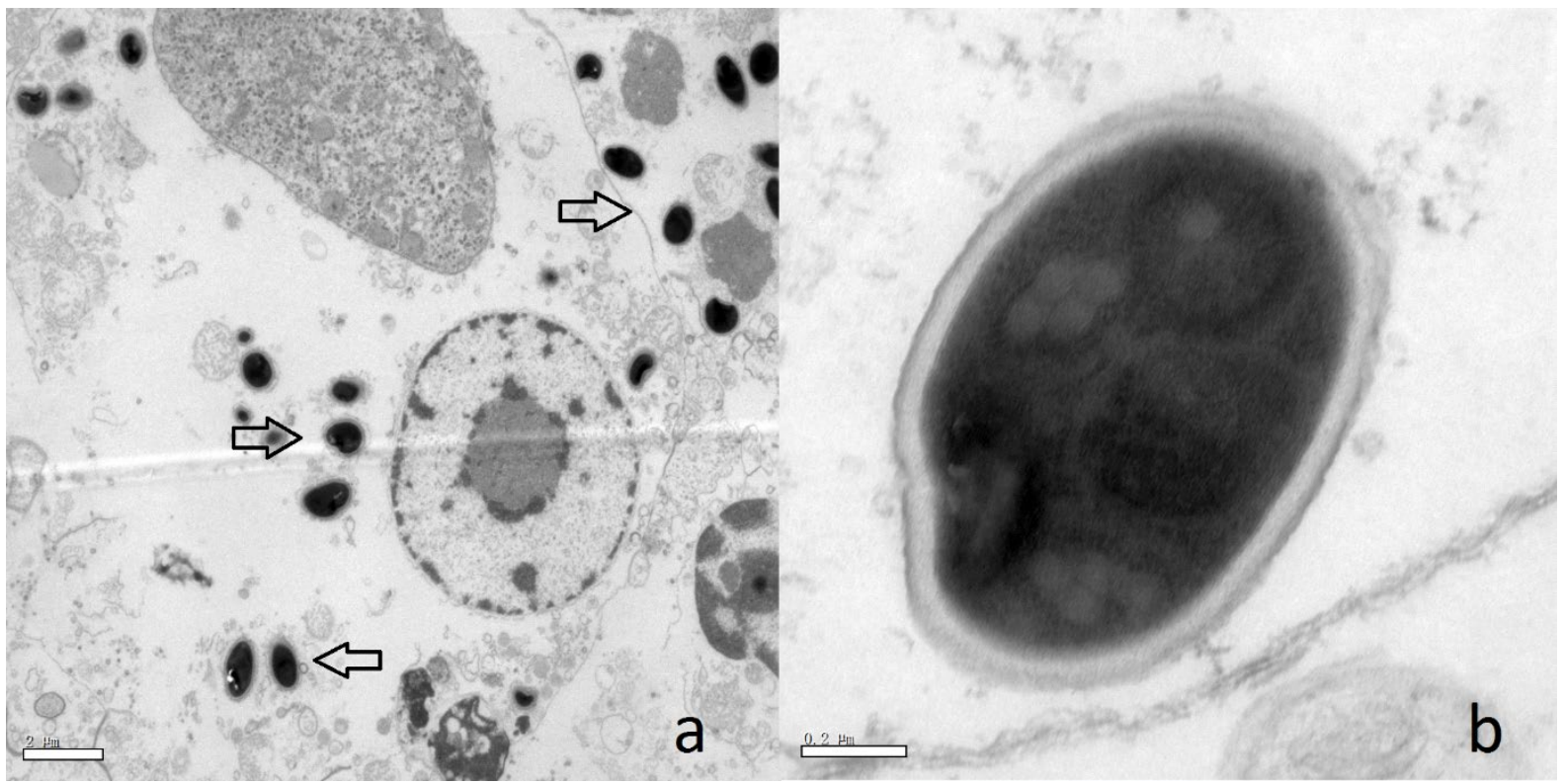

Figure 2: Transmission electron micrographs of different stages of Enterocytozoon hepatopenaei in hepatopancreatic tubule epithelial cells of $P$. vannamei. (a) Numerous sporoblasts. (b) A mature spore showing a cross section of the polar filament (PF).

\begin{tabular}{|c|c|c|c|c|c|c|c|c|c|c|}
\hline \multirow{2}{*}{ Nature of pond } & \multirow{2}{*}{ Nature of shrimp } & \multirow{2}{*}{ Length (cm) } & \multirow{2}{*}{ Weight (g) } & \multirow{2}{*}{ Number of shrimp } & \multicolumn{6}{|c|}{ Prevalence (\%) } \\
\hline & & & & & EHP & WSSV & IHHNV & AHPND & TSV & YHV \\
\hline \multirow{2}{*}{ Greenhouse ponds } & healthy & $10.70 \pm 1.23 a$ & $11.7 \pm 7.02 a$ & 160 & 5.3 & 0 & 0.63 & 0 & 0 & 0 \\
\hline & growth retardation & $8.79 \pm 2.46 b$ & $6.17 \pm 2.36 b$ & 200 & 93 & 0 & 4 & 1.5 & 0 & 0 \\
\hline
\end{tabular}

Table 2: Comparative prevalence of EHP in Penaeus vannamei collected from greenhouse ponds.
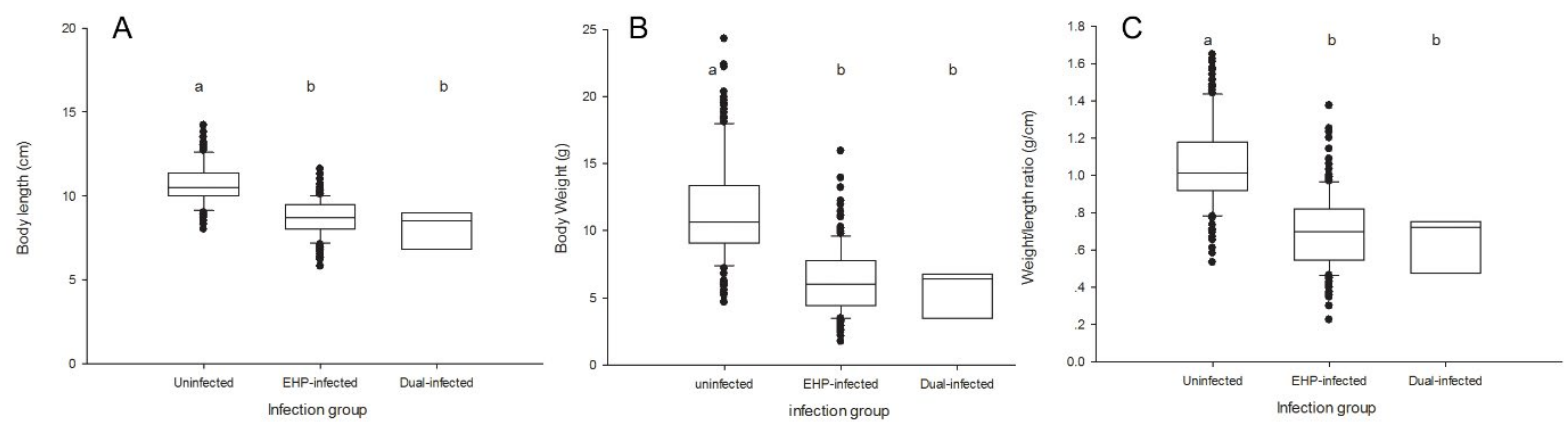

Figure 3: The comparison between uninfected, EHP infected, IHHNV infected, and dual infected groups.

(196 individuals) and dual infected group (infected with both of EHP and IHHNV) (7 individuals) were classified. BL of uninfected group was significantly higher than EHP infected group $(\mathrm{P}<0.05)$ and dual infected group $(\mathrm{P}<0.05)$ (Figure $3 \mathrm{~A})$. BL of EHP-infected group showed no significant different with that of uninfected group $(\mathrm{P}>0.05)$. Similar trends were observed for $\mathrm{BW}$ and $\mathrm{BW} / \mathrm{BL}$ ratio (Figures $3 \mathrm{~B}$ and $3 \mathrm{C}$ ).

\section{Discussion}

In this study, the prevalence of 6 pathogens were investigated among 360 shrimp individuals sampling from greenhouse ponds in Jiangsu province. Three pathogens, EHP, IHHNV and AHPND were detected, especially EHP were high prevalence in collected shrimps. The effects of EHP on shrimp industries were underestimated during the last 3 years since severe mortality caused by AHPND. EHP can be horizontally transmitted among shrimp not only by cannibalism $[16,17]$ but also by cohabitation with EHP-infected shrimp [18] meaning that infections can widespread in process of cultivation even in next generation of cultivation. With the growing of the economic losses due to EHP infection, EHP becomes a critical threat to shrimp aquaculture. In this study, the total positive rate of EHP infection was $54.4 \%$, suggesting that EHP prevalent seriously. However, prevalence of EHP infection in greenhouse ponds was much lower than that of in earthen ponds in Jiangsu Province (unpublished data). The characterizations of greenhouse ponds are independent with each other by plastic membrane and independent water circulation system, which can control EHP spread to a certain extent. Notably, Although 
AHPND spread quickly [4], it can also be properly controlled since the AHPND-infected ponds were immediately quarantined. In addition, the shrimp farmers taking greenhouse mode totally chose first generation post-larve that was SFP and selected for resisting of several pathogens, including WSSV, TSV and so on.

\section{Correlation between shrimp growth and pathogens}

EHP, as an emerge pathogen, was first reported as an unknown pathogen causing grow-retardation of black tiger shrimp, but it was not statistically associated with grow-retardation [19]. Although EHP has been commonly recognized as the pathogen associating with severe grow-retardation in P. monodon and P. vanname in recent years, statistical studies were also few reported to prove it. In this study, EHP infection is most common in grow-retarded shrimp specimens and BL, BW and BW/BL of EHP-infected groups were significantly lower than uninfected group in this study $(\mathrm{P}<0.05)$. Given the highly infection of EHP, it is reasonable to suggest that energy demand to support EHP [16]. Moreover, dual infection of IHHNV and EHP group was significantly lower than uninfected group in term of BW, BL and $\mathrm{BW} / \mathrm{BL}$ ratio $(\mathrm{P}<0.05)$, and was not significantly different with those of EHP-infected group $(\mathrm{P}>0.05)$. Although IHHNV can cause stunted growth in P. vannamei [20], Wang et al. [21] found that IHHNV had no relationship with body length of $P$. vannamei in Liaoning Province of China which is in agreement with our conclusion that growth of IHHNV-infected shrimp collected from earthen ponds in Jiangsu Province of China also was not influenced (unpublished data in another study). Thus, grow-retardation of dual infection group indicated that EHP had a significantly impact on the growth of $P$. vannamei in this study.

\section{Conclusion}

In conclusion, the shrimps collected from greenhouse ponds in Jiangsu Province of China were highly infected by EHP. Nevertheless, the prevalence of EHP in Greenhouse ponds (54.4\%) was much lower than that of in earthen ponds (79.5\%) (unpublished data), suggesting that characterization of Greenhouse ponds could in a certain extent control spread of pathogens. The cause of grow-retardation of $P$. vanname $i$ was resulted from EHP infection, since both of PCR and TEM revealed large number of EHP infected hepatopancreatic tubule epithelial cells of shrimp. The role of IHHNV in causing growth retardation seemed unlikely. Although prevalence of EHP in greenhouse ponds was in a certain extent declined in Jiangsu Province of China, effective measures should also be conducted, including SPF breeding stocks, strict pathogens quarantine, standard management strategies.

\section{Acknowledgements}

This study was supported by the project no. BE2017384 of the Jiangsu Province key research and development plan, project no. Y2017-20 of the fishery science and technology innovation program, project no. BN 2015120 of Northern Jiangsu province technology development program, project no. TG (16)099 of agriculture technology development of central government finance program. Thanks, are also due to anonymous reviewers for their valuable comments and suggestions.

\section{Reference}

1. Flegel TW (2012) Historic emergence, impact and current status of shrimp pathogens in Asia. J Invertebr Pathol 110: 166-173.

2. Soto-Rodriguez SA, Gomez-Gil B, Lozano-Olvera R, Betancourt-Lozano M, Morales-Covarrubias MS (2015) Field and experimental evidence of Vibrio parahaemolyticus as the causative agent of acute hepatopancreatic necrosis disease of cultured shrimp (Litopenaeus vannamei) in Northwestern Mexico. Appl Environ Microbiol 81: 1689-1699.

3. Nunan L, Lightner D, Pantoja C, Gomez-Jimenez S (2014) Detection of acute hepatopancreatic necrosis disease (AHPND) in Mexico. Dis Aqua Organisms 111: 81-86.

4. Tran L, Nunan L, Redman RM, Mohney LL, Pantoja CR, et al. (2013) Determination of the infectious nature of the agent of acute hepatopancreatic necrosis syndrome affecting penaeid shrimp. Dis Aqua Organisms 105: 45-55.

5. Sirikharin R, Taengchaiyaphum S, Sanguanrut $P$, Chi TD, Mavichak R, et al. (2015) Characterization and PCR detection of binary, Pir-Like toxins from Vibrio parahaemolyticus isolates that cause acute hepatopancreatic necrosis disease (AHPND) in Shrimp. Plos One 10: e0126987.

6. Kesavan K, Ravi M, Itami T, Raja S (2017) Quick report on prevalence of shrimp microsporidian parasite Enterocytozoon hepatopenaei in India. Aqua Res 48: 3980-3984.

7. Tang KF, Han JE, Aranguren LF, Whitenoble B, Schmidt MM, et al. (2016) Dense populations of the microsporidian Enterocytozoon hepatopenaei (EHP) in feces of Penaeus vannamei exhibiting white feces syndrome and pathways of their transmission to healthy shrimp. J Invertebr Pathol 140: 1-7.

8. Tourtip S, Wongtripop S, Stentiford GD, Bateman KS, Sriurairatana $\mathrm{S}$, et al. (2009) Enterocytozoon hepatopenaei sp. nov. (Microsporida: Enterocytozoonidae), a parasite of the black tiger shrimp Penaeus monodon (Decapoda: Penaeidae): fine structure and phylogenetic relationships. J Invertebr Pathol 102: 21-29.

9. Rajendran KV, Shivam S, Praveena P, Ezhil R, Joseph S, et al. (2016) Emergence of Enterocytozoon hepatopenaei (EHP) in farmed Penaeus (Litopenaeus) vannamei in India. Aquaculture 454: 272-280.

10. Santhoshkumar S, Sivakumar S, Vimal S, Majeed SA, Taju G, et al. (2016) Biochemical changes and tissue distribution of Enterocytozoon hepatopenaei (EHP) in naturally and experimentally EHP-infected whiteleg shrimp, Litopenaeus vannamei (Boone, 1931), in India. J Fish Dis 40: 529.

11. Ha NT, Ha TD, Nguyen, Thanh TV, Thi KL (2010) Enterocytozoon hepatopenae has been detected parasitizing tiger shrimp (Penaeus monodon) cultured in Vietnam and showing white feces syndrome (In Vietnamese with English abstract). J Agri Sci Technol 12: 40-50.

12. Flegel TW (2006) Detection of major penaeid shrimp viruses in Asia, a historical perspective with emphasis on Thailand. Aquaculture 258: 1-33.

13. Lo CF, Ho CH, Peng SE, Chen $\mathrm{CH}$, Hsu HC, et al. (1996) White spot syndrome baculovirus (WSBV) detected in cultured and captured shrimp, crabs and other arthropods. Dis Aqua Organisms 27: 215-225.

14. Tang KF, Navarro SA, Lightner DV (2007) PCR assay for discriminating between infectious hypodermal and hematopoietic necrosis virus (IHHNV) and virus-related sequences in the genome of Penaeus monodon. Dis Aqua Organisms 74: 165-170.

15. Tang KFJ, Lightner DV (2005) Phylogenetic analysis of Taura syndrome virus isolates collected between 1993 and 2004 and virulence comparison between two isolates representing different genetic variants. Virus Research 112: 69-76.

16. Tangprasittipap A, Srisala J, Chouwdee S, Somboon M, Chuchird N, et al (2013) The microsporidian Enterocytozoon hepatopenaei is not the cause of white feces syndrome in whiteleg shrimp Penaeus (Litopenaeus) vannamei. Bmc Veterinary Res 9: 139.

17. Rosa-Vélez JDL, Cedano-Thomas Y, Cid-Becerra J, Méndez-Payán JC Vega-Pérez C, et al. (2006) Presumptive detection of yellow head virus by reverse transcriptase polymerase chain reaction and dot-blot hybridization in Litopenaeus vannamei and L. stylirostris cultured on the Northwest coast of Mexico. J Fish Dis 29: 717-726.

18. Salachan PV, Jaroenlak $P$, Thitamadee $S$, Itsathitphaisarn $O$, Sritunyalucksana $\mathrm{K}$ (2016) Laboratory cohabitation challenge model for shrimp hepatopancreatic microsporidiosis (HPM) caused by Enterocytozoon hepatopenaei (EHP). BMC Veterinary Res 13: 9.

19. Chayaburakul K, Nash G, Pratanpipat $P$, Sriurairatana S, Withyachumnarnkul $B$ (2004) Multiple pathogens found in growth-retarded black tiger shrimp Penaeus monodon cultivated in Thailand. Dis Aqua Organisms 60: 89-96. 
Citation: Shen H, Jiang G, Wan X, Fan X, Qiao Y, et al. (2017) Multiple Pathogens Prevalent in Shrimp Penaeus vannamei Cultured from Greenhouse Ponds in Jiangsu Province of China. J Aquac Res Development 8: 516. doi: 10.4172/2155-9546.1000516

Page 5 of 5

20. Sakaew W, Pratoomthai B, Anantasomboon G, Asuvapongpatana S, Sriurairattana S, et al. (2008) Abdominal segment deformity disease (ASDD) of the whiteleg shrimp Penaeus vannamei reared in Thailand. Aquaculture 284 46-52.
21. Wang BY, Wang L, Liu MR, Shi-Gen YE, Rui-Jun LI, et al. (2017) Epidemiological investigation of three major viruses and Enterocytozoon hepatopenaei (EHP) in Pacific white leg shrimp Litopenaeus vannamei in Liaoning Province. J Dalian Ocean Uni 32: 150-154. 